\title{
Lack of tolerance to the protective effect of montelukast in exercise-induced bronchoconstriction in children
}

\author{
F.M. de Benedictis*, M.M. del Giudice", N. Forenza*, F. Decimo*, \\ D. de Benedictis* and A. Capristo\#
}

ABSTRACT: The effect over time of regular treatment with montelukast (MNT) in inhibiting exercise-induced bronchoconstriction (EIB) has never been evaluated in children. The aim of the present study was to examine the preventive effect of MNT against EIB in children at different time-points over a 4-week treatment period.

Thirty-two asthmatic children (aged 6-12 yrs) were enrolled in a double-blinded, randomised, parallel group design to receive a 4-week treatment with MNT (5 mg chewable tablets administered once daily in the evening) or placebo. Exercise challenge was performed at baseline and after 3, 7 and 28 days of treatment, 20-24 $\mathrm{h}$ after dosing.

MNT was significantly more protective than placebo against EIB at each time. The mean percentage drop of forced expiratory volume in one second (FEV1) was 24.6, 13.6, 12.0 and 11.6 for MNT, and 24.4, 22.4, 21.8 and 21.0 for placebo, at baseline and after 3, 7 and 28 days, respectively. For each drug, no significant difference in the percentage drop of FEV 1 was found between different days.

Regular treatment with montelukast provided significant protection against exercise-induced bronchoconstriction in asthmatic children over a 4-week period with no tolerance to the bronchoprotective effect.

\section{KEYWORDS: Exercise-induced bronchoconstriction, montelukast, tolerance}

xercise-induced bronchoconstriction (EIB) is a common manifestation of asthma in children and can interfere in their daily activities. The pathogenetic mechanism of EIB is not completely clear, but the release of inflammatory mediators from airway mast cells appears likely [1]. Although leukotrienes (LTs) have been inconstantly recovered from urine after exercise [2], the evidence for the role of these mediators in EIB derives from the bronchoprotective effect of anti-LT drugs [3].

Montelukast (MNT), a specific antagonist of cysteinyl-leukotriene (Cys-LT) receptors, showed a consistent effect against EIB in children when administered either as a single dose $[4,5]$ or as regular treatment [6]. In adults, a 12-week treatment with MNT attenuated the fall in pulmonary function following exercise with no tolerance to the bronchoprotective effect [7]. No study has evaluated the effect over time of regular treatment with MNT in inhibiting EIB in children. The present authors therefore examined the effect of once-daily MNT on EIB at several time-points during a 4-week treatment period.

\section{PATIENTS AND METHODS}

\section{Subjects}

A total of 32 children aged 6-12 yrs with mild-tomoderate asthma [8] were enrolled into the current study. Patients were recruited from the Depts of Paediatrics, at the University of Perugia and the University of Naples, Italy. The study protocol was approved by the institutional review boards of the two participating centres. Informed consent was obtained from patients and their parents.

At screening, all patients had a forced expiratory volume in one second (FEV1) of at least $75 \%$ of predicted and a decrease in FEV1 of at least $12 \%$ from the baseline after a standardised exercise challenge. Patients were not eligible for the study if they had been hospitalised for asthma within 3 months, had contracted a respiratory infection in the 4 weeks before the study, or were affected by other chronic respiratory diseases other than asthma. The use of any anti-asthma drug different from short-acting $\beta_{2}$-agonists within 1 month before the study was a reason for exclusion (except for patients already taking inhaled
AFFILIATIONS

Depts of *Paediatrics, University of Perugia, Perugia, and

\#University of Naples, Naples, Italy.

CORRESPONDENCE

F.M. de Benedictis

Dept of Paediatrics

"G. Salesi" Children's Hospital

Via Corridoni 11

60123 Ancona

Italy

Fax: 39715962234

E-mail: debenedictis@ao-

salesi.marche.it

Received:

February 102006

Accepted after revision:

April 162006 
steroids $200-400 \mu \mathrm{g}$ daily of beclomethasone dipropionate or equivalent, who were allowed to continue this dose unchanged throughout the study). Immunotherapy at a constant dose was permitted. Patients were withdrawn from the study if the treatment was interrupted for $>2$ consecutive days, if it was not administered in the evening before the exercise test day, if therapy with an excluded medication was initiated, or in the event of worsening asthma that required treatment with systemic steroids.

\section{Study design}

This was a multicentre, double-blinded, randomised, parallelgroup, placebo-controlled study. After screening, patients were assigned to receive MNT $5 \mathrm{mg}$ chewable tablet (Singulair, Merck, West Point, PA, USA) or matching placebo once daily at $\sim 20: 00 \mathrm{~h}$ for 4 weeks. Exercise challenge was repeated at $3 \pm 1,7 \pm 2$, and $28 \pm 3$ days after starting treatment, 20-24 $\mathrm{h}$ after dosing (the through point of the dosing interval). For each patient, every effort was taken to perform the exercise challenge at the same time of the day. Short-acting, inhaled $\beta_{2^{-}}$ agonists were withheld for $12 \mathrm{~h}$ before each exercise test.

\section{Exercise challenge}

The exercise test consisted of a 2-min warm-up and 6-min steady-state running on a treadmill (RAM of 770 Esoate, Padova, Italy) inclined to produce a heart rate of at least $85 \%$ of the maximum predicted for age (calculated as 220-age (yrs)) [9]. Small adjustments in workload (treadmill speed or grade) were made, if necessary, to achieve targeted hearth rates. Nasal clips were used during the test and heart rate was continuously monitored. Room temperature and relative humidity were measured and recorded. Differences of $1^{\circ} \mathrm{C}$ in temperature and $5 \mathrm{mg} \mathrm{H} \mathrm{H}_{2} \mathrm{O} \cdot \mathrm{L}^{-1}$ of air in humidity on the test days on each patient were considered acceptable [10]. At the discretion of the investigator, patients could receive an inhaled $\beta$-agonist for distressing symptoms at any time during or after exercise challenge.

\section{Pulmonary function measurement}

Pulmonary function was measured with a standard spirometer (Microlab 3300; MicroMedical Limited, Rochester, UK) according to accepted standards [11]. Predicted normal values for spirometry were obtained from the study by POLGAR et al. [12]. Measurements were performed before each exercise test (preexercise value) and then at 1, 5, 10, 15, 30 and 60 min after the end of the exercise. Heart rate was also measured at these timepoints. The exercise test was performed only if the pre-exercise FEV 1 was $\geqslant 70 \%$ of the mean predicted for the child's height.

The following parameters were calculated from the results of the pulmonary function tests:

Maximum percentage fall in FEV1=pre-exercise FEV1-lowest post-exercise FEV1/pre-exercise FEV1

\section{Percentage of protection $=(\mathrm{Pp}-\mathrm{Pt}) / \mathrm{Pp}$}

where $\mathrm{Pp}$ is the maximum percentage fall in FEV1 after placebo test, and $\mathrm{Pt}$ is the maximum percent fall in FEV1 after active treatment. Clinical protection was considered to have been obtained if the percentage fall in FEV1 after exercise with the drug was half or less than half of the percentage fall in FEV1 after the screening test [13]. Tolerance was defined as a significant difference from zero in the slope of the timeresponse profile of the treatment effect with days 3,7 and 28 for the end-point.

\section{Compliance}

Compliance was measured at each visit by counting the number of packages of tablets that were used, divided by the number of packages of tablets that should have been used during the specific time interval. For the purpose of the study, a compliance of $\geqslant 90 \%$ was considered acceptable.

\section{Statistical analysis}

Tolerance was the primary end-point, and it was assessed by comparing the rate of change over the 28-day treatment period for the end-point by using an ANOVA model that takes into account the variability within and between patients [14]. Unpaired t-test was used to compare the maximum decrease of FEV1 after exercise between the study groups. A paired $t$ test was used to analyse the within-group change of lung function from baseline. A 95\% confidence interval (CI) was constructed for the mean difference in the maximum percentage decrease of FEV1 between the MNT and the placebo group. Fisher's exact test was used to compare the number of patients who had clinical protection [15]. The study was designed to have $80 \%$ power (for 32 completing patients) to detect a difference between treatment groups of $50 \%$ in the fall of FEV1 after exercise, on the assumption that variability was similar to that observed in previous studies $[4,16]$. Differences were considered significant when $\mathrm{p}<0.05$.

\section{RESULTS}

Of the 32 patients enrolled in the study, 16 were randomly assigned to MNT and 16 to placebo group. One patient in the placebo group and another in the MNT group were withdrawn from the study because of worsening asthma and the need to take oral steroids. Thirty patients (18 males, 12 females), with a mean age of $9.9 \mathrm{yrs}$, represented the intent-to-treat population and were therefore considered for statistical evaluation. Two patients in the placebo group failed to attend the clinic on three occasions as a whole (one patient at days 7 and 28, the other at day 28). Seven of 30 patients were receiving inhaled steroids (table 1).

During the study days, room temperatures ranged $21-23^{\circ} \mathrm{C}$ and relative humidity $31-49 \%$. At screening, pre-exercise FEV1 values ranged $75-105 \%$, with no difference between groups: MNT (mean \pm SD) $90.0 \pm 10.0$, and placebo $86.2 \pm 6.8 \%$ of predicted values. For each group, there was no significant difference in pre-exercise FEV1 baseline values on different study days.

The mean $\pm \mathrm{SD}$ percentage drop in FEV1 was 24.6 \pm 12.3 , $13.6 \pm 12.9,12.0 \pm 9.7,11.6 \pm 11.1$ for MNT, and 24.4 \pm 7.7 , $22.4 \pm 6.4,21.8 \pm 7.3,21.0 \pm 5.7$ for placebo at screening test and after 3, 7 and 28 days of treatment, respectively (table 2). At screening, there was no difference in the percentage drop of FEV1 between MNT and placebo $(\mathrm{p}=0.096$; mean difference -0.15 ; 95\% CI -7.87-7.56). Conversely, a significant difference between the two drugs was observed at each time-point after treatment: day 3, $\mathrm{p}=0.026$ (mean difference $8.81 ; 95 \%$ CI 1.15 16.48; day 7, $\mathrm{p}=0.005$ (mean difference 9.83 ; 95\% CI 3.21-16.45); 


\begin{tabular}{|c|c|c|c|c|}
\hline \multicolumn{5}{|c|}{ Placebo } \\
\hline Patient no. & $\begin{array}{l}\text { Age } \\
\text { yrs }\end{array}$ & Sex & $\begin{array}{l}\text { FEV1 } \\
\% \text { pred }\end{array}$ & $\begin{array}{c}\text { Daily dose } \\
\mu g\end{array}$ \\
\hline \multicolumn{5}{|l|}{ Placebo } \\
\hline 1 & 11 & M & 83 & SLB intermittent \\
\hline 2 & 10 & M & 92 & SLB intermittent \\
\hline 3 & 12 & $\mathrm{~F}$ & 75 & FLT $100 \times 2$ \\
\hline 4 & 12 & $\mathrm{~F}$ & 91 & SLB intermittent \\
\hline 5 & 8 & $\mathrm{~F}$ & 95 & SLB intermittent \\
\hline 6 & 10 & M & 93 & SLB intermittent \\
\hline 7 & 11 & $\mathrm{~F}$ & 88 & BDS $200 \times 2$ \\
\hline 8 & 11 & M & 95 & SLB intermittent \\
\hline 9 & 11 & M & 88 & SLB intermittent \\
\hline 10 & 10 & M & 90 & SLB intermittent \\
\hline 11 & 10 & $\mathrm{~F}$ & 79 & SLB intermittent \\
\hline 12 & 10 & M & 77 & SLB intermittent \\
\hline 13 & 11 & M & 78 & SLB intermittent \\
\hline 14 & 10 & $\mathrm{~F}$ & 80 & FLT $100 \times 2$ \\
\hline 15 & 9 & $\mathrm{~F}$ & 89 & SLB intermittent \\
\hline \multicolumn{5}{|l|}{ Montelukast } \\
\hline 1 & 9 & $\mathrm{~F}$ & 77 & FLT $100 \times 2$ \\
\hline 2 & 12 & F & 98 & SLB intermittent \\
\hline 3 & 8 & M & 105 & BDS $200 \times 2$ \\
\hline 4 & 10 & M & 76 & SLB intermittent \\
\hline 5 & 11 & M & 92 & SLB intermittent \\
\hline 6 & 9 & M & 77 & BDS $200 \times 2$ \\
\hline 7 & 9 & M & 75 & SLB intermittent \\
\hline 8 & 12 & M & 100 & SLB intermittent \\
\hline 9 & 9 & M & 100 & SLB intermittent \\
\hline 10 & 12 & $\mathrm{~F}$ & 93 & SLB intermittent \\
\hline 11 & 8 & M & 100 & SLB intermittent \\
\hline 12 & 6 & $\mathrm{~F}$ & 85 & SLB intermittent \\
\hline 13 & 8 & $\mathrm{~F}$ & 95 & SLB intermittent \\
\hline 14 & 9 & M & 87 & SLB intermittent \\
\hline 15 & 9 & M & 91 & BDS $200 \times 2$ \\
\hline
\end{tabular}

FEV1: forced expiratory volume in one second; $\mathrm{M}$ : male; $\mathrm{F}$ : female; SLB: salbutamol; FLT: fluticasone; BDS: budesonide.

and day $28, \mathrm{p}=0.011$ (mean difference $9.47 ; 95 \%$ CI 2.37-16.58; fig. 1).

When the within-group change of FEV1 from baseline was analysed, a significant difference in the percentage fall of FEV1 after exercise was found for MNT (baseline versus day 3, $\mathrm{p}=0.007$; baseline versus day $7, \mathrm{p}=0.003$; baseline versus day 28 , $\mathrm{p}=0.008$ ), but not for placebo. For each group, no difference in the percentage fall of FEV1 was found between different study days (fig. 1). There was no difference in lung function changes after exercise between patients who were receiving or not receiving inhaled steroids.

Percentage of protection for MNT was 39, 44 and $44 \%$ after 3, 7 and 28 days, respectively. Clinical protection was provided in seven out of $15(46 \%)$ versus one out of $15(6 \% ; p<0.05), 10$ out of $15(66 \%)$ versus 0 out of $14(\mathrm{p}<0.005)$, nine out of $14(64 \%)$

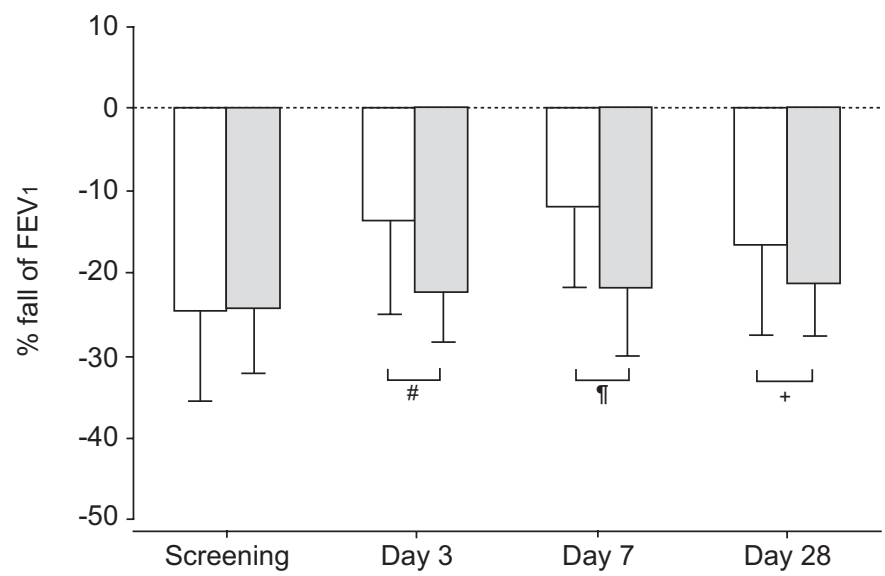

FIGURE 1. Mean percentage decrease of forced expiratory volume in one second $\left(F E V_{1}\right)$ at screening and at different time-points after treatment. $\square$ : montelukast; $:$ : placebo. ${ }^{\#}$ : $p=0.026 ;{ }^{\bullet}: p=0.005 ;^{+}: p=0.011$.

versus one out of $13(7 \% ; \mathrm{p}<0.005)$ patients treated with MNT or placebo after 3,7 and 28 days, respectively. No adverse events were seen. Compliance rates ranged $94-100 \%$ and were similar across treatment groups.

\section{DISCUSSION}

The present authors showed that once-daily treatment with MNT for 4 weeks provides significant protection against EIB compared with placebo with no tolerance.

The protective effect of MNT on EIB is in accordance with the results of previous studies in asthmatic children $[4,5,6,17]$ and further supports the role of Cys-LTs in the pathogenesis of EIB $[2,18]$. The percentage protection of MNT on EIB after 3 days of treatment was very close to that observed in other exercise studies, after a single dose [5] or two doses [4]. Data from the current study therefore confirm that long-term use of MNT is not a prerequisite for its efficacy on EIB. Although intermittent administration of this drug might be beneficial as either first-line or adjunct therapy in individuals in whom EIB is the primary manifestation of asthma [19], anti-inflammatory treatment should be instituted on regular basis.

The current study was the first to evaluate the effect of MNT against EIB at different time-points during regular therapy in children. In adults, 12-week treatment with MNT attenuated the fall in pulmonary function following exercise with no tolerance [7]. However, the time effect of MNT during the first 4 weeks of treatment, which may be a window for the onset of early tolerance, has not been formally evaluated. VILLARAN $e t$ al. [20] and EDELMAN et al. [21] examined the effect of MNT and salmeterol on EIB over an 8-week period. Protection by MNT was evident at day 3 and persisted throughout the whole treatment period without development of tolerance, while the effect of salmeterol appeared to wane over time. Unfortunately, the placebo group was not included in these studies, thus making the conclusions on lack of early tolerance to the bronchoprotective effect of MNT inconsistent.

The present study offers evidence that bronchoprotection induced by MNT is of similar magnitude after 3, 7 and 28 days. The finding that the degree of protection against EIB is 


\begin{tabular}{|c|c|c|c|c|c|c|c|c|}
\hline Patient no. & \multicolumn{2}{|c|}{ Screening } & \multicolumn{2}{|c|}{ Day 3} & \multicolumn{2}{|c|}{ Day 7} & \multicolumn{2}{|c|}{ Day 28} \\
\hline 1 & 13.2 & 12.6 & 22.1 & 15.9 & 16.5 & 20.2 & 23.0 & 22.6 \\
\hline 2 & 19.9 & 17.5 & 0.6 & 28.4 & 12.3 & 24.3 & 2.0 & 20.0 \\
\hline 4 & 53.4 & 35.0 & 37.7 & 23.1 & 8.3 & 38.2 & 11.7 & \\
\hline 5 & 22.3 & 25.0 & 21.1 & 20.5 & 10.7 & 23.2 & 21.4 & 11.7 \\
\hline 6 & 43.2 & 23.7 & 0 & 27.7 & 15.1 & 22.5 & 7.0 & 21.8 \\
\hline 7 & 34.8 & 21.5 & 43.4 & 19.6 & 44.4 & 22.9 & 43.2 & 23.4 \\
\hline 8 & 12.4 & 25.3 & 9.7 & 22.9 & 6.9 & 23.4 & 7.0 & 25.6 \\
\hline 9 & 20.2 & 25.8 & 14.2 & 22.2 & 16.7 & 16.7 & 8.4 & 20.0 \\
\hline 14 & 18.0 & 42.3 & 7.8 & 30.7 & 7.9 & 33.0 & 16.6 & 36.1 \\
\hline 15 & 16.0 & 24.1 & 8.2 & 24.3 & 7.2 & 15.8 & 7.4 & 20.3 \\
\hline Mean $_{ \pm}$SD & $24.6 \pm 12.3$ & $24.4 \pm 7.7$ & $13.6 \pm 12.9$ & $22.4 \pm 6.4$ & $12.0 \pm 9.7$ & $21.8 \pm 7.3$ & $11.6 \pm 11.1$ & $21.0 \pm 5.7$ \\
\hline
\end{tabular}

MNT: montelukast; PL: placebo.

not diminished over time differentiates MNT from other antiasthmatic agents and may result in relevant clinical advantage. Indeed, several studies highlighted that the extent of protection on EIB diminishes with the regular use both for shortacting and long-acting $\beta_{2}$-agonists [22]. Furthermore, in a placebo-controlled study of EIB in children, 12-week treatment with inhaled beclomethasone induced tolerance to the bronchoprotective effect [23].

A statistically significant effect of a drug on EIB does not necessarily indicate the effect is clinically important. Therefore, the clinical protection against EIB was also evaluated as an index of good clinical control. This analysis yielded the same results as that of the percentage decrease in FEV1 itself, and corroborates the role of MNT in the prevention of EIB. The rate of nonresponders to MNT varied from 54 to $36 \%$ at different times. No conclusions can be drawn about the clinical characteristics of such patients, since the present study was not designed to answer this question. Almost a quarter of the children in the current study were receiving regular treatment with inhaled steroids. These patients showed the same response as those who were not treated with these agents. On this point, it is relevant to note that tolerance to bronchoprotection afforded by anti-asthmatic drugs, such as $\beta_{2}$-agonists, is not prevented by concomitant inhaled steroid therapy [24].

The effect of MNT on baseline FEV1 was not significant in the current study. This finding has been found by other authors [6, 7] and might reflect the characteristics of patients in the current study who had normal lung function in the majority of cases. Some studies showed that MNT manifests a mild bronchodilator activity [25], but the protection against EIB afforded by this drug is independent of lung function values [7, 20]. This aspect supports the view that other factors in addition to smooth muscle inhibition play a role in drug-induced protection against exercise. Evaporative water loss from airway mucosa is considered an important mechanism in the pathogenesis of EIB as it may cause a transient change in osmolarity in the epithelial fluid, which subsequently induces the release of inflammatory mediators [26].

No significant difference in the percentage fall of FEV1 after exercise was observed on the screening or placebo days, indicating that subjects remained responsive to exercise throughout the study period. In the placebo group, the fall of FEV1 at different time-points was universally (except for two cases) less than half of the screening value for each patient, thus explaining that exercise-induced reduction in lung function was also reproducible for individuals.

In conclusion, regular once-daily treatment with montelukast does not appear to reduce the protective effect on exerciseinduced bronchoconstriction over time and may represent a preferential therapeutic option for chronic treatment of exercise-induced bronchoconstriction in children.

\section{REFERENCES}

1 McFadden ER, Gilbert IA. Exercise-induced asthma. N Engl J Med 1994; 330: 1362-1367.

2 O'Byrne PM. Leukotriene bronchoconstriction induced by allergen and exercise. Am J Respir Crit Care Med 2000; 161: S68-S72.

3 Drazen JM, Israel E, O'Byrne PM. Treatment of asthma with drugs modifying the leukotriene pathway. $N$ Engl J Med 1999; 340: 197-206.

4 Kemp JP, Dockhorn RJ, Shapiro GG, et al. Montelukast once daily inhibits exercise-induced bronchoconstriction in 
6- to 14-year-old children with asthma. J Pediatr 1998; 133: 424-428.

5 Peroni DG, Piacentini GL, Ress M, Bodini A, Loiacono A, Boner AL. Time efficacy of a single dose of montelukast on exercise-induced asthma in children. Pediatr Allergy Immunol 2002; 13: 434-437.

$6 \mathrm{Kim} \mathrm{JH,} \mathrm{Lee} \mathrm{SY,} \mathrm{Kim} \mathrm{HB,} \mathrm{et} \mathrm{al.} \mathrm{Prolonged} \mathrm{effect} \mathrm{of}$ montelukast in asthmatic children with exercise-induced bronchoconstriction. Pediatr Pulmonol 2005; 39: 162-166.

7 Leff JA, Busse WW, Pearlman D, et al. Montelukast, a leukotriene-receptor antagonist, for the treatment of mild asthma and exercise-induced bronchoconstriction. N Engl J Med 1998; 339: 147-152.

8 National Asthma Education and Prevention Program. Expert Panel Report II: Guidelines for the diagnosis and management of asthma. Bethesda, MD, National Institutes of Health, 1997.

9 American Thoracic Society, Guidelines for methacholine and exercise challenge testing - 1999. Am J Respir Crit Care Med 2000; 161: 309-329.

10 Anderson SD, Schoeffel RE, Follet R, Perry CP, Daviskas E, Kendall M. Sensitivity to heat and water loss at rest and during exercise in asthmatic patients. Eur J Respir Dis 1982; 63: 459-463.

11 Standardization of spirometry, 1994 update. American Thoracic Society. Am J Respir Crit Care Med 1995; 152: 1107-1136.

12 Polgar G, Promadhat V. Pulmonary Function Testing in Children: Techniques and Standards. Philadelphia, WB Saunders, 1971.

13 Silverman M, Anderson SD. Standardization of exercise tests in asthmatic children. Arch Dis Child 1972; 47: 882-887.

14 Laird NM, Ware JH. Random-effects model for longitudinal data. Biometrics 1982; 38: 963-974.

15 Altman DG. Practical statistics for medical research. London, Chapman and Hall, 1991.

16 Bronsky EA, Kemp JP, Zhang J, Guerriero D, Reiss TE. Dose-related protection of exercise bronchoconstriction by montelukast, a cysteinyl leukotriene-receptor antagonist, at the end of a once-daily dosing interval. Clin Pharmacol Ther 1997; 62: 556-561.

17 Melo RE, Solè D, Naspitz CK. Exercise-induced bronchoconstriction in children: montelukast attenuates the immediate-phase and late-phase responses. J Allergy Clin Immunol 2003; 111: 311-317.

18 Reiss TF, Hill JB, Harman E, et al. Increased urinary excretion of LTE4 after exercise and attenuation of exercise-induced bronchospasm by montelukast, a cysteinyl leukotriene receptor antagonist. Thorax 1997; 52: 1030-1035.

19 Coreno A, Skowronski M, Kotaru C, McFadden ER. Comparative effect of long-acting beta2-agonists, leukotriene receptor antagonists, and a 5-lipoxygenase inhibitor on exercise induced asthma. J Allergy Clin Immunol 2000; 106: 500-506.

20 Villaran C, O'Neill SJ, Helbling A, et al. Montelukast versus salmeterol in patients with asthma and exercise-induced bronchoconstriction. J Allergy Clin Immunol 1999; 104: 547-553.

21 Edelman JM, Turpin JA, Bronsky EA, et al. Oral montelukast compared with inhaled salmeterol to prevent exerciseinduced bronchoconstriction. Ann Intern Med 2000; 132: 97-104.

22 Nelson HS. Is there a problem with inhaled long-acting betaadrenergic agonists? J Allergy Clin Immunol 2006; 117: 3-16.

23 Freezer NJ, Croasdel H, Doul IJM, Holgate ST. Effect of regular inhaled beclomethasone on exercise and methacholine airway responses in school children with recurrent wheeze. Eur Respir J 1995; 8: 1488-1493.

24 Simons FER, Gerstner TV, Cheang MS. Tolerance to the bronchoprotective effect of salmeterol in adolescents with exercise-induced asthma using concurrent inhaled corticosteroid treatment. Pediatrics 1997; 99: 655-659.

25 Reiss TF, Chervinsky P, Dockhorn RJ, Shingo S, Seidenberg B, Edwards TB. Montelukast, a once-daily leukotriene receptor antagonist, in the treatment of chronic asthma. Arch Intern Med 1998; 158: 1213-1220.

26 Carlsen KH, Carlsen KC. Exercise-induced asthma. Paediatr Respir Rev 2002; 3: 154-160. 